\title{
UNA POÉTICA EN SEIS POEMAS
}

Fermín HERRERO

En vez de predicar sin más, en esta ocasión voy a dar entre medias de este intento de poética, supongo que nulo como los precedentes, algo de trigo. He elegido para hilvanar la justificación teórica de mi quehacer media docena de poemas, entre los muchos metapoéticos que he perpetrado, casi siempre como pórtico y faro de mis cerca de veinte libros editados, que se corresponden con derroteros y miradas diversos, por si pudieran conformar en su complementariedad heterogénea una especie de visión de conjunto, de haberla.

Este tiempo ya no nos pertenece pues de distinto modo pensamos bordear los años, la ceguera. Para qué pintamos en los muros horizontes si un micrófono ahora influye más que cien razonamientos fulminantes. Ha llegado el invierno de improviso. Los aeropuertos están cerrados, pero las azafatas se maquillan sumisas sobre las camas de nogal, porque apremian los cuernos y pronto empezará la montería. -DE CÓMO LA PERPLEJIDAD CADUCA-Cuando llegó el amanecer del primer día salieron de los bosques con sus labios de musgo para desentrañar la luz. Yo sé que las palabras se enquistaron de pronto como ortigas en un corral sin dueño. Cómo expresar la nitidez del cielo admirando el furor de postreras riadas. Bajaron hasta el mar que anegaba con liquen las roquedas, aquellas margas que antiguamente delimitaron pastizales. Los más jóvenes sólo conocían un silencio engendrado en agua. Años después olvidaron el prodigio y al ver las nubes discutían sobre el progreso de los paraguas.-ARGUMENTO-

(Echarse al monte)

Tengo la convicción de que todos los poetas, de serlo, son póstumos, a las pruebas a lo largo de la historia me remito, con lo que no es determinante la recepción que lo publicado tenga en el tiempo que les tocó vivir. Es más, con relativa frecuencia la escasa comprensión de sus escritos en vida y el haber seguido una trayectoria a su aire, sin apoyarse en grupos o capillas, no obra sino a su favor. No obstante, opino que todo escritor que aspire a serlo debe dejar un testimonio de su época. Tal fue mi intención, hará la friolera de un cuarto de siglo, cuando me salió Echarse al monte.

Este poema inicial marcaba el desarrollo del libro, desde el desencanto y estupor de partida al saber que nuestros ídolos nos habían engañado por completo, que su ideario maniqueo no era sino un trampolín para encaramarse al poder y de qué manera, hasta las cacerías para chanchullear continuaban. Hay que tener en cuenta que durante el golpe del 23F yo estudiaba COU. La exaltación prístina de haber salido del diluvio que todo lo limpia y regenera se tornó estupefacción al enterarnos de que a partir de entonces nadie escaparía al negocio de los paraguas y a la tentación del espectáculo, de su estulticia a micrófono abierto, salvo los que decidieron suicidarse poco a poco o de repente. Bien es cierto que para los sobrevivientes a los días heroicos y frágiles -bueno, para mí, no conviene nunca 
arrogarse del plural- ese estupor no ha hecho sino aumentar con la consolidación de la partitocracia, con siglas de todo signo convertidas en empresas de colocación y empleo, y el pensamiento único, sea la organización que sea, de trepar y quítate tú para ponerme yo. Y, lo que es peor, sabiendo que las alternativas suelen conducir al totalitarismo.

Luego pienso ahora que lo escribí en su día, al margen de lo testifical, en legítima defensa contra el lenguaje vacío del poder y de sus aliados pedagógicos, sociológicos, sicológicos..., para destapar sus añagazas y mecanismos, mediante la ironía, la parodia de los hueros discursos establecidos -hoy metamorfoseado en las homilías castradoras de lo políticamente correcto, no sé, desde la democracia en el arte al feminismo.

No recuerdo muy bien por qué, me imagino que seguramente por mi ingenua voracidad expresiva del momento, cuando todo me parecía poco, recurrí al "poema doble" que, al hilo, me permitía un dialogismo diverso, en consonancia con la complejidad creciente de nuestro mundo en cuanto a la multiplicidad de voces y su interacción babélica. Esta innovación formal que, aunque parezca mal decirlo, creo que nadie más ha usado, la apliqué también en El tiempo de los usureros, otro libro abiertamente testimonial y frente a las doctrinas imperantes, tanto a diestro como a siniestro, y luego ya la he abandonado. Se la ofrezco a cualquier joven con ganas que huya de la moda de poesía adolescente, blandengue, por ser suave, y de un narcisismo confesional; sus posibilidades, en cuanto a ampliación, rechazo, esquinamiento, apostilla, etc., respecto al poema único proverbial, son cuantiosas.

\author{
Donde amapola, di ababol y, si se puede, cardo. Y al vino, \\ vino. Donde collado, altozano o alcor, otero, \\ escribe llanamente cerro, alto o cuesta, loma. No digas \\ lo que nunca se dijo, lo que no se dice \\ en tu pueblo. Más vale mayo frío, la paja \\ poca y el trigo mucho. No impongas a la tarde \\ la añoranza si es falsa o aprendida, anota \\ simplemente el silbido del viento \\ en los linares. No recuerdes la muerte aunque \\ te tenga, piensa que de tanta mies se emboza \\ el peine cada día, que eres este momento. Y al vino \\ vino, sólo la miga, el tuétano. Tampoco \\ hables más de la infancia para embaucar \\ al olvido, precisa la orfandad del muérdago \\ en el hayedo. Más vale mayo frío. Si tempero, \\ arraigas; si membrillo, aromas; si cierzo, tiritas. Di \\ berro, ortiga; di bálago, acebal. No niegues la palabra \\ amor, tampoco entrega, ni prodigio, ni tú. Ahora \\ bien, antes de escribirlas, hazlas.
}

- CATASTRO -

(El tiempo de los usureros)

"Catastro" se titula así porque la única propiedad verdadera de los poetas son las palabras, para mí, especialmente las terruñeras, aquéllas que oí de chiquillo y de pronto recuerdo con todo lo que arrastran. En realidad, más que el vocabulario, que también, son los giros y expresiones de un idioma campesino ya desaparecido lo que me lleva a recobrar la emoción que presagia la llegada de lo poético. 
Para ello es necesario utilizar el término exacto, preciso, decantado durante siglos. En poesía no puede haber sinónimos y cada palabra tiene su propia historia, personal y literaria. Ésa es la apreciación del arranque del poema: "amapola", aparte de ser un vocablo sobado y resobado líricamente y, dicho sea de paso, no hay poesía original, es decir, poesía, si se limita a los caminos trillados, designa la visión estética de la flor, mientras que "ababol" es la manera tradicional usada en mi tierra por los labradores, desde una perspectiva agrícola. Es la misma planta con idéntica flor, pero el campesino ve en ella una hierba mala que perjudica a las cebadas y trigales, por lo que debe eliminarla, antes con escardillo y ahora con herbicidas.

Pero como digo, más que el léxico, lo que me interesa son las mañas enunciativas del castellano viejo, que defiendo en el poema acogiéndome a lo pueblerino, en la estela de aquello que ya dijera el Arcipreste de Hita: "En todos los tus fechos, en fablar e en ál,/escoge la mesura e lo que es comunal". Por eso he optado en parte de mi poesía, en fin, lo he pretendido, naturalmente sin conseguirlo, me daría con un canto en los dientes de haberme acercado mínimamente, por un fraseo escueto, acaso áspero, bronco, sordo, como quien atravesara un terronal desabrido con la íntima convicción de que se dirige, que ya lo lleva, a un lugar habitable.

Esta dicción quebrada a la que he tratado de arrimarme, llena de elipsis y sobreentendidos, es la sintaxis castellana, de los pueblos de la Meseta, que oí de niño y que ha desaparecido junto a la cultura agraria en que fraguó. Tal vez el elogio más grande, amén de exagerado, qué más quisiera, que se ha hecho de mi poesía, fruto de la generosidad del gran escritor barcelonés José Ángel Cilleruelo, fue que está escrita inequívocamente en castellano, no en español. De rebote, pienso que esa manera de expresarse es genuinamente poética por cuanto en un poema es más importante que el significado de las palabras lo que éstas se dicen entre sí y, aún más, lo que son capaces de callar.

La manera abrupta de hablar se refleja también en el texto en el aspecto métrico. Es una de las razones por las que recurro con frecuencia, incluso en ocasiones siempre, al encabalgamiento, recurso en apariencia simplón, sencillo de glosar, a tal punto que en todos los comentarios de texto se señala, claro que limitándose a establecer un recuento o censo, pero sin duda más complejo, al menos es lo que más trabajo una vez que tengo el poema esbozado. Como prueba de esta afirmación bastaría el extraordinario estudio al respecto del profesor de la Universidad de León José Enrique Martínez titulado La voz entrecortada de los versos, que sólo citaré por tratarse de un tema que da para mucho. Ya en el Renacimiento Fernando de Herrera, entre otros, reparó en sus posibilidades expresivas y concluyó que es "uno de los caminos principales para alcanzar la alteza y hermosura del estilo". Aduciré otros dos motivo de esta decisión rítmica: mi devoción por la articulación de los poemas de Claudio Rodríguez y su vínculo con el caminar, y la eficacia del encabalgamiento para evitar o por lo pronto mitigar el soniquete si, como es mi caso, se elige el apoyo de los metros clásicos.

Y no debe olvidarse, por resumir la cuestión, que el encabalgamiento es lo que puede diferenciar un poema en prosa de uno en verso, si ambos, como suele suceder, están medidos de forma clásica, porque permite diferenciar la pausa ortográfica ajustada a la medida del verso de la pausa versal. A partir de ahí, existen encabalgamientos léxicos, rítmicos, etc, sería muy enojoso profundizar por ese 
camino de "cocina" poética. Pero como decía es lo que más me cuesta a la hora de dar con la forma definitiva, de tal manera que mis poemas están medidos, por así decirlo, dos veces, al jugar con esas posibilidades. El problema añadido es que esta circunstancia sólo se nota oyéndolos.

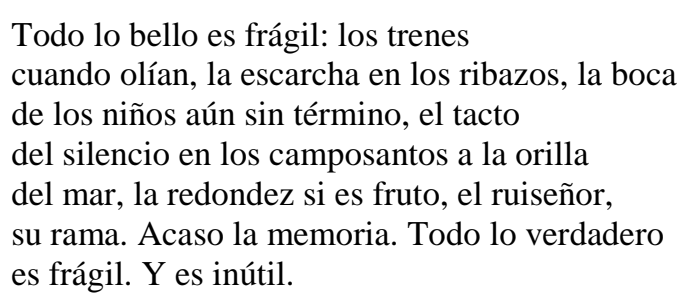

(El tiempo de los usureros)

Este poema es un ejercicio de clase. Cada curso, para aproximarse a la naturaleza del género lírico, que suele despacharse con aquello de la expresión en verso de sentimientos y pensamientos, ahora ya ni siquiera eso, puesto que la literatura ha sido absorbida y capitidisminuida en los programas de enseñanzas medias por la lengua y en el mejor de los casos reducida a historia de la literatura, les propongo a los alumnos que piensen y escriban cinco imágenes concretas que para ellos representen, concentren, la belleza del mundo, en cuanto les han emocionado o conmovido, tras explicarles que la poesía trabaja contra la muerte y por tanto tiene la obligación de celebrar la existencia en todos los órdenes. A continuación les pido que elijan dos adjetivos que juzguen indefectiblemente unidos a lo sustantivo de la belleza y, por último, que con estos mimbres escriban un texto en prosa o en verso que nos sirva para acercarnos un poco al concepto de poesía y reflexionar sobre ella.

Un año, mientras los escolares se afanaban, me puse yo mismo al tajo. Debido al desenfreno lírico que he mentado al glosar el primer poema, añadí una imagen más y casi otra y también me pasé en la adjetivación. Veamos la procedencia y significado de lo que me vino a la cabeza, por ser indicativo de la noción misma de poesía que en aquel entonces más o menos me bullía por dentro.

La referencia ferroviaria sin duda, más allá de lo estético, procede de la lentitud, pues la experiencia contemplativa la asocio inconscientemente con aquellos regionales propulsados a gasoil y no con los veloces, inodoros y asépticos trenes actuales en los que parece, poco menos que en los aviones, que se viajara en el limbo, sin saber muy bien por dónde se va ni en qué pararse a ver, es imposible, por la ventanilla.

La segunda percepción me lleva, por una parte a la simbología oriental, tan querida por mí. De haber podido, hubiera deseado ser un poeta menor de la Dinastía Tang perdido en la montaña, lo que nos conduce al adjetivo "inútil", como opuesto a la visión pragmática y monetaria del mundo, y espero que algo se note de este amor a la poesía japonesa y, sobre todo, china, naturalmente antiguas, en la que el rocío se identifica con la fugacidad de la vida, con lo efímero de la existencia, lo que nos llevaría al calificativo de "frágil". Tiendo a pensar esto porque el sintagma se completa con el término "ribazo" y el complemento del nombre a buen seguro se debe a que es ahí, siempre y cuando miren a oriente y no caigan en umbría, donde antes se regala la escarcha por efecto del sol; por otra, a que la belleza de la blancura heladora destaca más en los planos inclinados del campo. 
La alusión a la boca de los niños y a la pureza de su lenguaje, todavía sin malear, responde, en la línea del famoso aforismo rilkeano en el que contempla la niñez como la patria del poeta, a la exigencia de mantener en el poema la inocencia primigenia con la que venimos al mundo y que conservamos, hasta en el lenguaje, durante la infancia. Un tanto en contraste, como excipiente de silencio y quietud eternos, la imagen posterior remite a ciertos cementerios cántabros, si bien supongo que, de fondo, me rondaban el cementerio marino, escrito y real, de Paul Valéry, muy cercano por cierto, en el que reposa, al de Colliure. De cariz más netamente literario es lo relativo al ruiseñor, que viene sobre todo de Keats, igual que el adjetivo "verdadero" aplicado a la belleza, recordando aquellos inmortales versos finales de "Oda a una urna griega". En cuanto a la redondez, si bien no descarto que me acuciara la frase de aquel jefe indio sioux, creo: "todas las cosas tienden a ser redondas", funcionaría como metonimia de lo que fructifica y naturalmente del vientre femenino en estado de buena esperanza, traería al poema la granazón del amor, lo único que nos puede salvar de la devastación del tiempo y del aniquilamiento de la muerte.

Escucha a los alisos. Eres viento. Allí donde
te encuentres, sea en esta orilla o disertando
sobre el ser y la nada, eres viento. El río
te desnuda en su empuje de finitud, si bien
del mismo modo vas desnudo por tus caprichos
y por tus sueños. Parva bajo la parva
el hombre puja sin mirar atrás, le parece
que nada debe, te parece. No queda gesto
alguno en la memoria, con los años. Escucha
al viento, óyete, es malo andar sin compañía.

(La gratitud)

La gratitud es un libro -y, para bien o para mal, no publico colecciones de poemas unidos en atadijo, sino libros unitarios, cuyo tono y sentido se van urdiendo en mí hasta que siento la necesidad de procurar escribirlos como buenamente puedo- que concebí como una manera necesaria, también y sobre todo para la vida, de salirse de sí y de librarse de uno mismo para volcarse ("gratitud y pensamiento tienen el mismo origen", reza uno de los microlitos de Paul Celan) en un tú múltiple, incluido el milagro constante de la vida, con lo que por añadidura pretendía realzar un sentimiento tan denostado (Stalin opinaba que la gratitud es una enfermedad que sufren los perros) y en desuso como el que escogí para el título.

Así que, como no podía ser de otra manera, el primer poema, que en relación con el inciso previo, como es natural, suele funcionar en mis libros a modo de poética de los mismos, parte del esclarecido Eclesiastés y su vanidad de vanidades todo vanidad, de la que poco tienen, por otro lado, que hablarnos a los poetas, pues bien conocemos nuestro sometimiento a sus rastreras veleidades. Somos, sin duda, viento y nada más ("el viento, las asechanzas y la pálida imagen de la muerte", nos recuerda de continuo Petronio, en un mundo que es, en virtud de la inolvidable metáfora del divino Bocángel "república de viento, que tiene por Monarca un accidente") y, sin embargo... 
Si las poéticas no se dan en verso por exigencia íntima, sino que se elaboran, como estoy medio haciendo, a posteriori, no dejan de ser coartadas, de ahí su peligro. Me limitaré sólo, en este sentido, a aclarar algo anecdótico a partir del poema y que afecta únicamente a una palabra: aliso.

Elegí este árbol, que nunca había visto hasta que reparé en él en una zona a la orilla del Duero a su paso por la provincia de Valladolid y del que me sorprendió en primera instancia su porte elegante, porque observándolo, noté, en conexión con el símbolo del viento que lo acompaña bíblicamente en el primer verso, de qué manera tan peculiar pasaban por sus ramas los aires. Mientras que, al lado del corro de alisos ribereños, los pinos piñoneros lo enjambraban o muy cerca un plantón de álamos lo hacían inequívocamente cantor, a la manera machadiana, los alisos es como si filtrasen y cernieran delicada, musicalmente el viento, tal cedazo que cribase con sutil paciencia el grano de las pajuzas.

Pues bien, años más tarde decidí presentar el libro al premio Gil de Biedma y al ponerme a afinarlo en la medida de lo posible a tal efecto, de inmediato me vino a la cabeza el poema "Ribera de los alisos" y el caserón forestal semiderruido en el pinar cercano a Coca, junto al Eresma, por cuyos alrededores había andado no hacía mucho pensando en el autor de la generación del 50, "un pequeño rincón en el mapa de España/que me sé de memoria, porque fue mi reino", y me imaginé, ingenuo de mí, que de obtener el galardón, como al final, por impensable fortuna, sucedió, bien se podía interpretar como un guiño al autor de Moralidades.

Item más. Mucho tiempo después, descubrí en uno de los memorables diarios del sabio José Jiménez Lozano este apuntamiento: “Toda la oferta del mundo, según el Arcipreste, para seducir al hombre es la sombra de un aliso, que simboliza las promesas del mundo, para Qohelet todo es humo de humo, niebla de nieblas, vapor de agua de vapores de agua, para Job hierba que enseguida se agosta y arroja al horno. Pero el Arcipreste es sin duda muy católico y pese a todo, encuentra algún encanto en tan escasa sombra, porque algo es algo". Busqué enseguida la procedencia de la mención al de Hita, al que cito de nuevo: "Non perderé yo a Dios nin al su paraíso/por pecado del mundo, que es sombra de alyso".

Y entonces supe, por fin, el porqué de mi preferencia por un árbol que apenas conocía al escribir el poema.

En cualquier fuentecilla del monte está el misterio, la creación. Las palabras que oíste son mentiras repetidas, mercancía, artificio. Ya lo ves, lo natural fluye, se da; se da la conjunción que eleva sin intérpretes ni retórica y bien está que así sea. Y que pase. De manera que alejarse es no volver, qué lástima el río que ha sido manadero, qué lástima.

(De la letra menuda)

Tengo siempre presentes, aun siendo consciente de lo inalcanzable de su cumplimiento, de ahí la lástima que cierra doblada el poema, las palabras de Blas Pascal: "Cuando uno se encuentra con un 
estilo natural se asombra y se entusiasma, porque esperaba encontrarse con un autor y se ha encontrado con un hombre".

Tampoco olvido nunca la máxima terrenal del que, sin ir más lejos, en apariencia, sólo en apariencia apocado, se encamina hacia lo cósmico, del impar Alberto Caeiro: "desde mi aldea veo todo lo que desde la tierra se puede ver del universo". Desde luego, creo que a partir de "un único paisaje en el alma: aquél que primero le dio a ésta su dimensión", y ahora acudo al para mí no menos decisivo Miguel Torga, se puede levantar un mundo, una manera de entender el vivir, aunque sea tan acotado -la visión inicial e iniciática que tuvieron por la ventana de su cuarto, por caso- como, no sé, un cerrete coronado por una carrasquilla en el caso de mi paisana cineasta Mercedes Álvarez según su maravillosa película El cielo gira o simplemente un árbol para el pintor Ramón Gaya, admirable por tantas cosas.

$\mathrm{Y}$ es que, en definitiva, de muy poco, de casi nada, estoy seguro respecto a la poesía. Pero sí de que, de ser, está. Y está en todo, particularmente en lo pequeño, lo menudo, lo inadvertido. Cómo he llegado al cabo de tantos lustros de rellenar renglones cortados a esta perogrullada, a esta simpleza tan manifiesta, tan absoluta, tan de estribillo de las Rimas ("podrá no haber poetas pero siempre...") sería muy largo de explicar: con mis primeros libros creo que fui hasta el finisterre de lo metafórico, me asomé al abismo de lo hermético, me vi a mí mismo y retrocedí, eso sí, después de lo recorrido no pude darme la vuelta, voy marcha atrás de cara.

El inciso "de ser" se debe, a grandes rasgos, a que esta especie de enfermedad, trastorno o afección religiosa de orden patológico, esta manía de protección de lo sagrado (José Luis Puerto dixit), de lo trascendente, no sé, de lo espiritual, que perturba a ciertos individuos débiles de la especie, seguramente no sea, sin más, sino un espejismo. Ahora bien, qué bello, glorioso incluso, no hay ninguno que se le parezca ni de lejos. Lo de "está", porque estoy convencido de que la poesía, pese a la opinión contraria generalizada, no procede de uno mismo, sino que existe y significa siempre y en todo, sólo hay que recogerla, poniendo el máximo cuidado heideggeriano en no mancillarla, o en hacerlo lo menos posible.

De tal manera que prefiero "creación" a "mundo", vocablo que tiendo a identificar con la historia de la humanidad, con los tejemanejes de las apetencias propias y ajenas, con la prisa, el ajetreo y los adelantos, con el frenesí social, la opinión pública..., con lo falsario, en suma, de lo que hablaba al principio. Vuelvo al inigualable Gaya: "La naturaleza ha escapado a la historia, nosotros no hemos podido".

No necesito reinventar o fijar vidas, en cuyo caso me daría a lo narrativo o épico, sino tratar de explicarme, sólo tantear, lo que hay. Acompaño por este sendero que se aleja del mundanal ruido a Antonio Machado: "No desdeñéis la palabra; el mundo es ruidoso y mudo, poetas, sólo Dios habla". Y me permito, al paso, un paréntesis etimológico a tener en cuenta: creación viene de poiesis, término que Platón fija en 'El banquete' como "la causa que convierte cualquier cosa que consideremos de noser a ser". Y su discípulo Plotino remacha: "La naturaleza es sólo una imagen o imitación de la sabiduría, que es lo que está más allá del alma”. Y otra vez Gaya: "Nosotros, por lo visto, estamos cansados, gastados y también eso que se llama estar...en crisis. La naturaleza, en cambio, cada mañana 
aparece, amanece, no ya de nuevo, sino por primera vez, inédita.”. Así cualquier manantial de agua purísima que nos sorprende en la ladera del monte. Y no hay más.

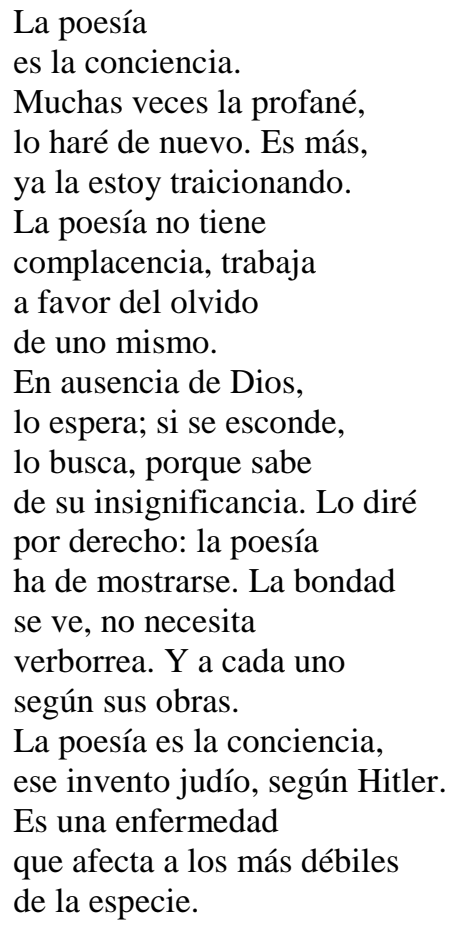

(Sin ir más lejos)

Como principio, en el verso inicial de Sin ir más lejos, establezco una identificación plena de la poesía con la conciencia, decisiva para el tono, el clima, del resto del poemario. Pero, ¿de qué conciencia hablamos?, ¿a qué conciencia me refiero? Para empezar, vete a saber lo que es la conciencia, de la misma manera que a ver quién es el listo que define el alma, aunque en su día hubiera alguien tan temerario que incluso estimara su peso exacto en gramos. Voy a intentar explicar qué acepción de conciencia apliqué, más o menos, aquí, en relación con la cita previa del filósofo japonés de la singular, en cuanto integradora del pensamiento oriental y occidental, escuela de Kioto Nishida Kitarō: "El yo como el unificador de la conciencia no es el sujeto gramatical".

Quizá para deslindarlo con cierta precisión sea conveniente antes determinar los posibles sentidos de conciencia que escapan a mi intención: la buena o mala conciencia propia consecuencia de la lucha conmigo mismo, o la conciencia social ("la conciencia del hombre no se mueve en el mundo, sino el mundo en ella”, esgrime Gómez Dávila en uno de sus escolios), en mi caso cabe suponer que burguesa o, bueno, de clase media medio ilustrada.

Fue una estancia corta, pero crucial, en la India la que me proporcionó la clave desde la que entender vagamente lo que buscaba, lo que pretendía captar con este libro. No me extenderé en lo anecdótico ni relataré cómo lo intuí y en cierto modo lo concreté en Delhi y Calcuta. Lo que advertí se corresponde aproximadamente con el término "Ahamkāra", para cuya aclaración acudo al magisterio de la poeta e indóloga Chantal Maillard: "sabia delimitación que el sistema sāmkhya introdujo entre la mente y la conciencia. La mente (manas): el sentido que aúna las percepciones 
proporcionadas por los otros cinco, y la conciencia (buddhi): la capacidad de ver la realidad externa que los sentidos construyen y asistir, además a esta construcción". En esta parte final está el meollo del asunto, sin duda. A seguido, la propia Maillard puntualiza: "El observador que, retirándose, fuese capaz de situarse convenientemente podría llegar a comprender el funcionamiento del universo". He ahí la tarea, por lo demás imposible, que debe acometer el poeta. Para, al cabo, preguntarse: “¿Qué yo sería aquel que observase desde una conciencia despojada del yo?".

Mucho antes, había leído en el texto sagrado budista Bhagavad-gītā esta reflexión no menos reveladora en relación a lo que vengo cavilando: "Como ser pensante, me es posible suprimir y ahogar en mi conciencia cada movimiento de autoafirmación, cada noción y opinión que es simplemente mía, cada deseo que me pertenece, y llegar a ser el médium puro de mi pensamiento que es universal; en una palabra, no vivir más mi propia vida, sino dejar que mi conciencia sea inundada y poseída por la vida Eterna e Infinita del Espíritu".

Vuelvo a la cuestión capital planteada por Maillard. Entiendo aquí la conciencia cercana a este modo oriental, separada, emancipada del yo y capaz de trascenderlo, una percepción tan leve como precisa, tan honda como sencilla, acumulada a la manera, por caso del inconsciente colectivo de Jung, a lo largo de generaciones, fruto de la tradición que se hereda y transustancia en una mirada original.

Tampoco estaría muy lejos de la formulación benjaminiana del aura, que según Alberto Giordano es "un suceso impersonal, algo que ocurre instantáneamente entre un objeto que ha empezado a brillar y un sujeto fascinado por este brillo, y que no se explica por las propiedades de aquél o por las aptitudes de este". Desde luego, se ve que no hay que recurrir a lo oriental para apreciaciones que se nos antojan ajenas a nuestra cultura acaso por su escasa difusión y perceptibilidad, no quiero ni pensar que sea por su hondura. De manera lateral, pero importante para apuntalar lo que argumento, el filósofo Juan Arnau apunta que "Bergson sostiene que hay conciencia en el origen de la vida y que esa conciencia no es sino una exigencia de creación", justamente la que impele al poeta cuando siente la necesidad de escribir. Y se podría seguir con las especulaciones de Merleau-Ponty en torno a las localizaciones de la conciencia.

Hans Jonas, el gran amigo de Hannah Arendt, hasta el juicio a Eichmann y las repercusiones de su acuñación de "la banalidad del mal", repara por su parte en que "ni siquiera el registro más completo del estado exterior de un cerebro hasta en sus estructuras y mecanismos más finos permitiría sospechar la participación de la conciencia, si no la conociéramos por la propia existencia interior, es decir, por la conciencia misma". Claro que tangencialmente alega, me parece que cargado de razón, aunque eso sea otro cantar, que "para poder incluir esta dimensión interior en todo el cuadro, como es necesario, puesto que ha surgido en el proceso natural y aparece en formas naturales, debemos retomar desde el principio nuestro propósito de dar cuenta del ser, es decir, la cuestión cosmológica."

Ortega y Gasset sostenía que lo que llamamos conciencia es lo más raro que hay en el universo. Y tanto. Para muchos es un epifenómeno nato, que escapa a la senda de la evolución y de la selección natural, aunque, quién nos lo iba a decir, a criterio de D. H. Lawrence el hombre sea "una gran aventura de la conciencia". Se encuentra adormecida en el mineral o en el vegetal, aunque hasta esto es 
discutible, y si no que les consulten a quienes han probado la psilobicina o el ácido lisérgico qué percibieron en la naturaleza. Diríase que el proceso de crecimiento de la vida ha resultado del trabajo de la conciencia por elevar la materia, que la aplastaba. El ser vivo representaría de facto su despertar y en el hombre hay una vía primordial de escape y retorno, que le proporcionaría la expresión poética, cuanto más denotativa y menos connotativa, a mi juicio, mejor.

Esta conciencia recogería a mayores, como dije antes, una resonancia, de largo alcance, de la creación. Por consiguiente participaría de una alegría intrínseca deudora del mero existir y podría servir para desterrar o cuando menos combatir la vacua vanidad, el pecado mayor que trae aparejado el mester lírico. Sería por su propia sustancia, libre, la libertad misma, y su poder en cada individuo es inmenso, inimaginable, puesto que dependemos por completo de ella.

Si a esta idea inicial del poema le injertamos un sustrato, un componente ético, que no moral, en la línea de pensadores como Ricoeur, Buber, Gebser, Hersch o Lévinas (como posdata a lo anterior qué mejor que este dictamen suyo legítimamente epifánico: "la conciencia es la contemporaneidad del instante consigo mismo"), tendríamos el andamiaje que sostiene el texto y el libro en su conjunto, al delimitar desde dónde está pensado y espero que escrito. No otro es el propósito de la inclusión de la frase atribuida a Hitler y no conviene olvidar que todo poeta contemporáneo debe tener siempre en cuenta la admonición de Hölderlin sobre la finalidad de recurrir a la poesía en tiempos, como los decimonónicos y aún peor los nuestros, de miseria espiritual y la no menos severa y trascendental de Adorno sobre si se puede escribir poesía después de Auschwitz. 